\title{
Navigated odontoid screw placement using the 0 -arm: technical note and case series
}

\author{
Jared M. Pisapia, MD, ${ }^{1}$ Nikhil R. Nayak, MD, ${ }^{1}$ Ryan D. Salinas, MD, ${ }^{1}$ Luke Macyszyn, MD, MA, ${ }^{2}$ \\ John Y. K. Lee, MD, MSCE, ${ }^{1}$ Timothy H. Lucas, MD, PhD, ${ }^{1}$ Neil R. Malhotra, MD, ${ }^{1}$ \\ H. Isaac Chen, MD, ${ }^{1,3}$ and James M. Schuster, MD, PhD'
}

\begin{abstract}
1Department of Neurosurgery, University of Pennsylvania, Philadelphia, Pennsylvania; ${ }^{2}$ Departments of Neurosurgery and Orthopedics, UCLA Medical Center, Santa Monica, California; ${ }^{3}$ Department of Neurosurgery, Philadelphia VA Medical Center, Philadelphia, Pennsylvania
\end{abstract}

OBJECTIVE As odontoid process fractures become increasingly common in the aging population, a technical understanding of treatment approaches is critical. 3D image guidance can improve the safety of posterior cervical hardware placement, but few studies have explored its utility in anterior approaches. The authors present in a stepwise fashion the technique of odontoid screw placement using the Medtronic $\mathrm{O}$-arm navigation system and describe their initial institutional experience with this surgical approach.

METHODS The authors retrospectively reviewed all cases of anterior odontoid screw fixation for Type II fractures at an academic medical center between 2006 and 2015. Patients were identified from a prospectively collected institutional database of patients who had suffered spine trauma. A standardized protocol for navigated odontoid screw placement was generated from the collective experience at the authors' institution. Secondarily, the authors compared collected variables, including presenting symptoms, injury mechanism, surgical complications, blood loss, operative time, radiographically demonstrated nonunion rate, and clinical outcome at most recent follow-up, between navigated and nonnavigated cases.

RESULTS Ten patients (three female; mean age 61) underwent odontoid screw placement. Most patients presented with neck pain without a neurological deficit after a fall. 0-arm navigation was used in 8 patients. An acute neck hematoma and screw retraction, each requiring surgery, occurred in 2 patients in whom navigation was used. Partial vocal cord paralysis occurred after surgery in one patient in whom no navigation was used. There was no difference in blood loss or operative time with or without navigation. One patient from each group had radiographic nonunion. No patient reported a worsening of symptoms at follow-up (mean duration 9 months).

CONCLUSIONS The authors provide a detailed step-by-step guide to the navigated placement of an odontoid screw. Their surgical experience suggests that $\mathrm{O}$-arm-assisted odontoid screw fixation is a viable approach. Future studies will be needed to rigorously compare the accuracy and efficiency of navigated versus nonnavigated odontoid screw placement.

http://thejns.org/doi/abs/10.3171/2016.5.SPINE151412

KEY WORDS odontoid; O-arm navigation; screw fixation; cervical spine

$\mathrm{O}$ DONTOID process fractures comprise 10\%-20\% of all cervical spine fractures, ${ }^{18,22}$ of which Type II fractures, as described by Anderson and D'Alonso, ${ }^{2}$ are the most common. These fractures through the base of the odontoid process are unstable and unlikely to heal without intervention, especially in patients with the following risk factors: age over 50 years, displacement of the dens greater than $5 \mathrm{~mm}$ relative to the C-2 body, angulation greater than $10^{\circ}$, translation greater than $4 \mathrm{~mm}$, and failure to maintain alignment with external mobiliza-

ABBREVIATIONS AP = anterior-posterior; EBL = estimated blood loss; $\mathrm{PEG}=$ percutaneous endoscopic gastrostomy . SUBMITTED November 25, 2015. ACCEPTED May 25, 2016.

INCLUDE WHEN CITING Published online August 12, 2016; DOI: 10.3171/2016.5.SPINE151412. 
tion. ${ }^{12}$ Although the most appropriate means of fixation remains debated, ${ }^{7}$ most choose to treat the majority of Type II odontoid fractures surgically to reestablish the stability of the atlantoaxial complex and to restore alignment to promote healing..$^{23,24}$

Unstable Type II odontoid fractures may be surgically treated through several approaches. Gallie- and Brookstype fusions ${ }^{5,10}$ are forms of posterior sublaminar $\mathrm{C} 1-2$ wiring that require intact $\mathrm{C}-1$ and $\mathrm{C}-2$ arches, and they may be combined with a $\mathrm{C} 1-2$ transarticular screw fixa$\operatorname{tion}^{13}$ to reduce rotational movement. An alternative is the Harms-type fusion, which involves placement of C-1 lateral mass and C-2 pars or pedicle screws joined by rods. ${ }^{14}$ Finally, an odontoid screw is well suited for fractures in which a fracture line in an anterosuperior to posteroinferior orientation. ${ }^{4}$ Anterior fixation has the benefits of being an osteosynthetic technique that provides fixation directly across the fracture site and preserves normal $\mathrm{C} 1-2$ rotational motion that is lost when posterior $\mathrm{C} 1-2$ fusion is performed. ${ }^{3,18}$ For the success of all of these techniques, accurate and safe screw placement is required, but this can be difficult in the setting of trauma.

Several groups have therefore increasingly employed intraoperative 3D image guidance via the O-arm (Medtronic, Inc.) or Airo (Brainlab) system combined with a surgical navigation system and optical tracking of instruments, as adjuncts to hardware placement in spine surgery., $, 15,19,20,27$ Such adjuncts are meant to increase the safety and accuracy of screw placement. While there have been reports of Oarm navigation for posterior fixation in the upper cervical spine, including C-1 lateral mass, C-2 pars, pedicle screws, and laminar screws,,${ }^{11,16}$ no studies are devoted solely to the study of anterior fixation for odontoid fractures. Thus, the purpose of this paper is to present in a stepwise fashion the technique for odontoid screw placement using the O-arm surgical navigation system. In addition, we describe our surgical experience in treating patients with $\mathrm{O}$-arm navigation, along with illustrative cases, to demonstrate nuances of the technique and to provide an initial assessment of its relative safety and effectiveness.

\section{Methods}

A standardized protocol for navigated odontoid screw placement was generated from the collective experience of all authors. We retrospectively reviewed data for all consecutive patients undergoing odontoid screw fixation for Type II dens fracture at a single academic medical center between 2006 and 2015. Patients were identified from a prospectively collected institutional database on spine trauma. The study was approved by the Institutional Review Board of the University of Pennsylvania, and a waiver of consent was obtained. The following variables were extracted from the medical record: demographics, mechanism of injury, presenting symptom, preoperative neurological status, use of intraoperative $\mathrm{O}$-arm and navigation, estimated blood loss (EBL), procedure time, surgical complications, discharge destination, and symptoms and neurological status at the time of most recent followup. All pre- and postoperative imaging studies were reviewed. The decision to use the O-arm system was based on surgeon preference and availability of the technology. Surgical procedures were performed as described below. Fusions were assessed by standing plain anteroposterior (AP) and lateral radiographs at the time of follow-up, and CT scanning of the cervical spine was performed for any patient with clinical symptoms or suspicion of nonunion. Patient follow-up status was obtained at the time of most recent office visit. A standardized descriptive system, the EQ-5D, was applied retrospectively to assess healthrelated quality of life states in all patients. It consisted of 5 dimensions-mobility, self-care, usual activities, pain/ discomfort, and anxiety/depression-and each dimension was graded from 1 to 3 , with an increasing number corresponding to an increasing level of severity. Descriptive statistics were used to characterize the patient population and outcomes.

\section{Surgical Technique \\ Positioning}

Following fiberoptic intubation on a hospital bed or stretcher, a radiolucent Mayfield skull clamp is applied with bilateral pins located two fingerbreadths above the pinna and in line with the tragus. The patient is then transferred to the flat Jackson table in the supine position. The Mayfield adapter or C-flex (Fig. 1) is used to connect the Mayfield clamp to the table. A rolled towel is placed transversely under the shoulders to extend the patient at the cervicothoracic junction. Using the Mayfield adapter, the head is overall extended to facilitate the trajectory of odontoid screw placement. The crown of the head is then slightly flexed in an attempt to reduce the displaced odontoid tip. Patient positioning in this manner is crucial to enable the proper odontoid screw trajectory to be obtained. The cervical collar is removed. The Medtronic Vertek arm and passive frame are attached to the Mayfield clamp. The final position of the patient is best appreciated by the surgeon standing several feet away from the bed observing the patient from a lateral view (Fig. 2). Next, the O-arm (Medtronic, Inc.) is introduced (Fig. 3). It is used to obtain AP and lateral plain radiographs to check the degree of extension. Images are viewed on the StealthStation navigation system (StealthStation S7, Medtronic Inc.), which is positioned adjacent to the patient's head. A radiopaque instrument such as a towel clamp may be taped to the upper chest and lower neck to simulate the screw trajectory. Once positioning is adequate, the $\mathrm{O}$-arm is removed or may be pushed in the cranial direction above the patient's head.

\section{Exposure}

The patient is prepared and draped in the usual sterile fashion. The passive frame is covered with a Lahey bag or equivalent and secured with a rubber band. The incision is marked within a skin crease on the anterior neck at the level of the thyroid cartilage corresponding approximately to C5-6. The incision is usually placed on the right side of the neck, although it may be placed on the left side in cases of prior right neck surgery. An incision is made to the level of the platysma, which is then divided using Bovie electrocautery. The platysma is undercut superiorly and 


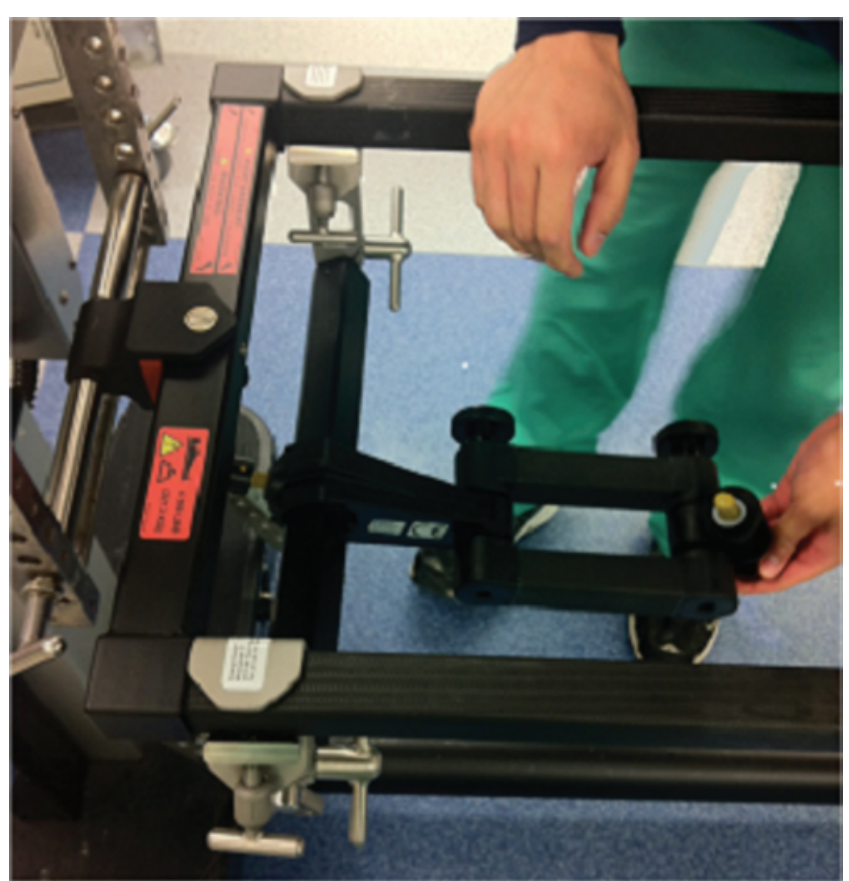

FIG. 1. Mayfield adapter. The Mayfield skull clamp is attached to the yellow screw on the Mayfield adapter, which secures the patient to the Jackson table. Figure is available in color online only.

retracted with a self-retaining retractor. The dissection is carried down the medial aspect of the sternocleidomastoid muscle using scissors and Debakey forceps. The carotid artery is palpated, and handheld Cloward retractors are used to retract the carotid artery, jugular vein, and vagus nerve laterally while an assistant retracts the trachea and esophagus medially. Dissection is continued down to the anterior aspect of the vertebral bodies and superiorly using blunt dissection. Electrocautery is used to mobilize the longus colli muscles laterally off the anterior surface of the vertebral bodies, taking care to avoid the disc spaces. Shadow-line retractors are used to retract tissue. For localization, a spinal needle is placed in the anticipated C2-3 disc space. The $\mathrm{O}$-arm is covered with the $\mathrm{O}$-arm drape and brought back into the field. AP and lateral plain radiographs are obtained using the $\mathrm{O}$-arm to confirm the appropriate level. A full $\mathrm{O}$-arm spin is then performed to generate $\mathrm{CT}$ images. The $\mathrm{O}$-arm is then pushed to the cranial portion of the field.

\section{Screw Placement}

The handheld Stealth probe is registered to the Stealth machine. It then is used to determine the starting point for the odontoid screw and its trajectory. The desired screw trajectory may be saved as a plan on the Stealth system. The Midas Rex pneumatic drill (Medtronic, Inc.) with an AM-8 drill bit is used to drill a midline trough in the superior aspect of $\mathrm{C}-3$ and inferior aspect of $\mathrm{C}-2$. The trough is created to accommodate the head of the odontoid screw. A drill guide is placed in the trough, and the drill, which is registered to the Stealth system, is used to drill from the anterior aspect of C-3 vertebral body through C-2 to-

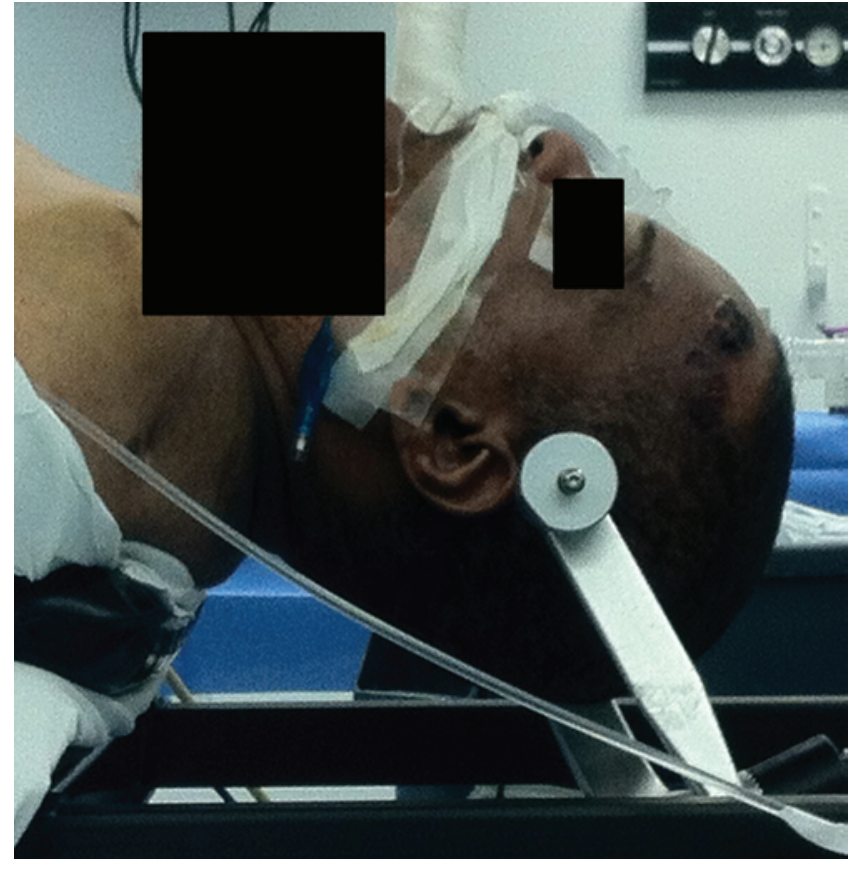

FIG. 2. Lateral view of head position. The Mayfield adapter is used to position the neck in an overall extended position to facilitate the screw trajectory, while the addition of mild head flexion may aid in reducing a displaced fracture. Black boxes are added to the image to obscure identifying facial features. Figure is available in color online only.

ward the tip of the odontoid process (Fig. 4). The course of the drill is guided by the planned screw trajectory saved in the navigation system (Fig. 5). As an additional check, $\mathrm{AP}$ and lateral fluoroscopy is performed using the O-arm every $5 \mathrm{~mm}$ to ensure in real time that the actual position of the drill matches the planned trajectory (Fig. 6). Although this step is not performed uniformly, we recommend it as a safety check, rather than relying solely on the planned trajectory. The built-in ability to obtain AP/

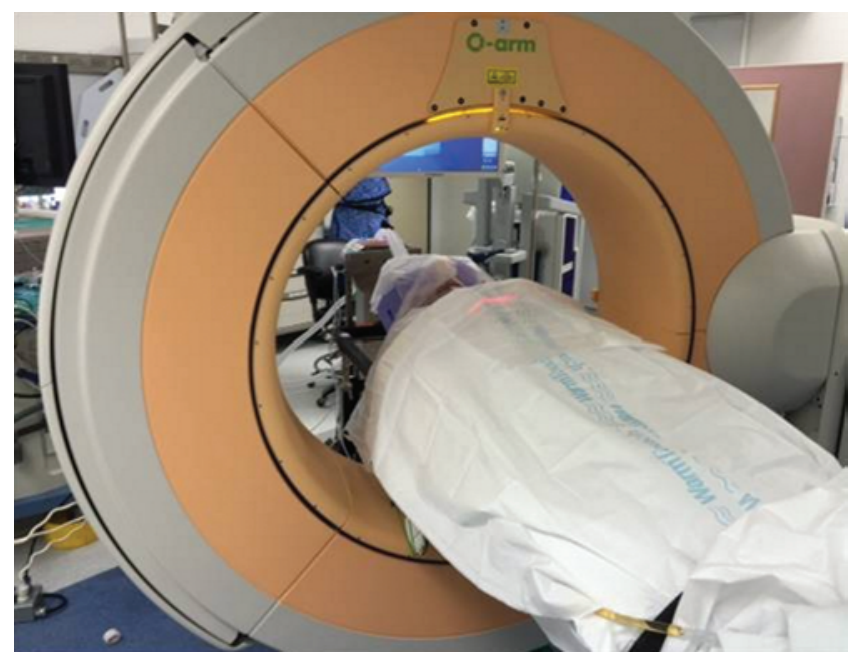

FIG. 3. O-arm. The O-arm is initially used to obtain AP and lateral plain radiographs to assess patient positioning. Figure is available in color online only. 


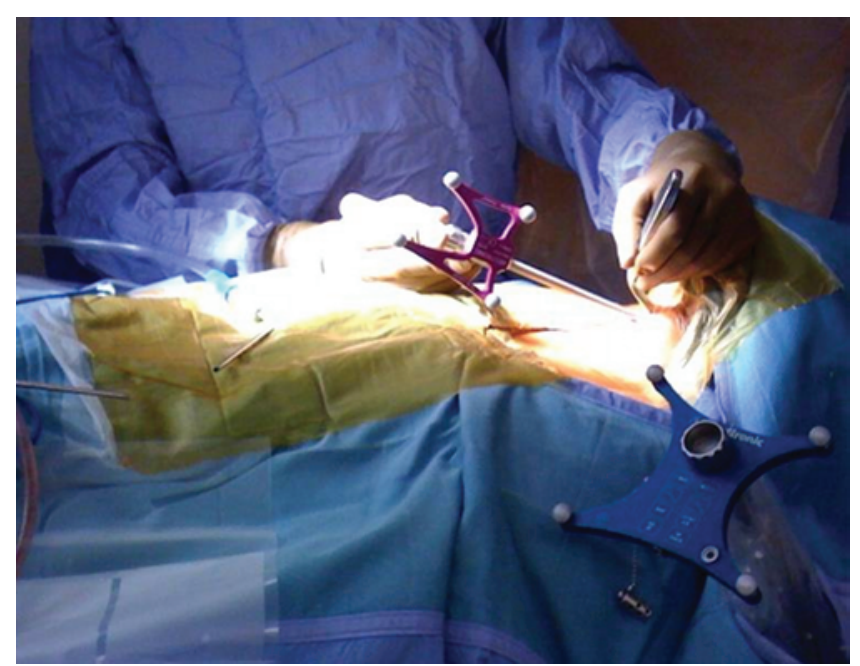

FIG. 4. Intraoperative photograph showing the navigated drill guide. The navigated drill guide, shown with purple attachment, is inserted into the neck incision. It is used to plan a virtual screw trajectory. Note the passive reference frame attached to the Vertek arm positioned at the cranial part of the operative field (lower right corner of the intraoperative photograph). Figure is available in color online only.

lateral radiographs with the $\mathrm{O}$-arm obviates the need to remove the O-arm from the field and introduce a separate biplanar fluoroscopy machine. The drill is then removed. The appropriate screw length is chosen based on the measured length from the inferior aspect of C-2 to the tip of the odontoid process using intraoperative $\mathrm{O}$-arm-generated CT images. A lag screw is favored for reduction of a displaced fracture. The screw is introduced using a screw guide, and it is allowed to find its path. Intermittent AP and lateral plain radiographs are taken using the $\mathrm{O}$-arm to confirm its trajectory. Whereas navigation and fluoroscopy are used during drilling, fluoroscopy alone is used during screw insertion since the planned trajectory is static and does not change in real time. The screw is inserted so that its head is flush with the anterior aspect of the C-2 and C-3 vertebral bodies. Retractors are removed and an $\mathrm{O}$-arm spin is performed after screw placement to confirm its position and reduction of the fracture.

\section{Closure}

Hemostasis is obtained. A surgical drain may be placed. The subcutaneous layer is closed with 3-0 Vicryl interrupted sutures, and the skin is closed with a 4-0 Biosyn running subcuticular stitch. The wound is covered with steri-strips, followed by gauze and a Tegaderm. The cervical collar is replaced at the end of the case.

\section{Results}

We identified 10 patients ( 3 female, mean age 61) who underwent odontoid screw placement for Type II odontoid fractures at our institution (Table 1). Seven of the patients presented with neck pain following a fall, 1 had a history of a mild neurological deficit, and 3 were asymptomatic. The $\mathrm{O}$-arm navigation was used in 8 cases $(80 \%)$, and fluoroscopy alone without navigation was used in

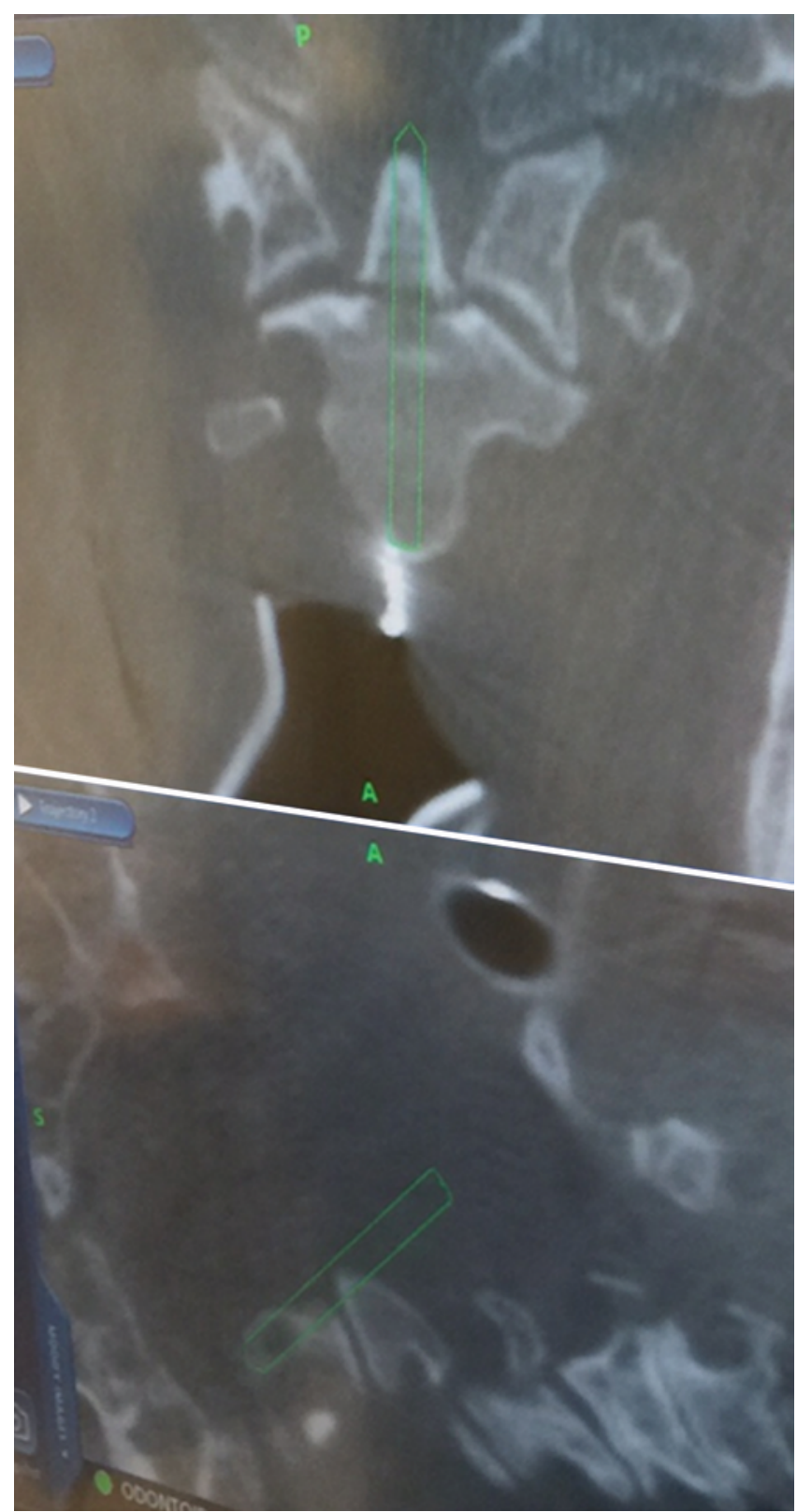

FIG. 5. Screen shot showing screw trajectory in coronal (upper) and sagittal (lower) planes. The sagittal image is oriented in the patient's supine position (left cranial, right caudal). The screw trajectory is determined using the stealth handheld probe and may be saved on the Medtronic navigation system. It is used to guide the drill prior to screw placement. Figure is available in color online only.

the remaining 2 cases (20\%). Repositioning of an odontoid screw was never performed. One patient undergoing $\mathrm{O}$-arm navigation developed an acute neck hematoma requiring surgical evacuation. In another case in which navigation was used, the patient underwent percutaneous endoscopic gastrostomy (PEG) for continued chronic dysphagia, whereas in a case in which navigation was not used, the patient underwent PEG for partial vocal cord paralysis. No significant difference was noted in mean EBL between the two groups; on average, EBL was $42.5 \pm 11$ 


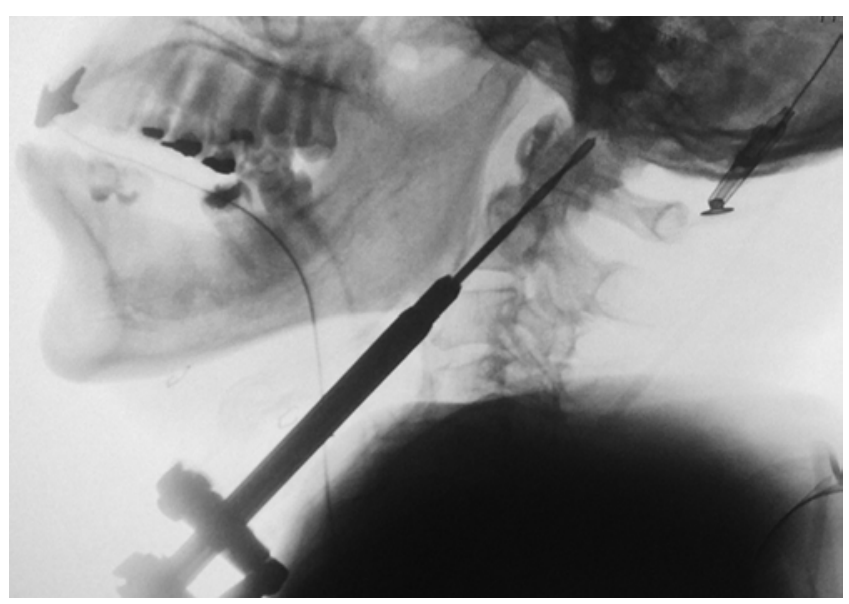

FIG. 6. Screen shot of lateral plain radiographs obtained sequentially during drilling. AP and lateral plain images using the fluoroscopy feature of the $\mathrm{O}$-arm are obtained at 5-mm intervals during drilling and screw placement.

$\mathrm{ml}$ in nonnavigated cases and $41.4 \pm 24 \mathrm{ml}$ in navigated cases $(p=0.95)$. Although no significant intergroup difference was noted in mean procedural time, there was a trend toward shorter times for navigated cases; odontoid screw placement took a mean of $138 \pm 113$ mins in the navigated cases versus $199 \pm 24$ mins in the nonnavigated cases $(p=0.16)$. In Case 2 , in addition to navigated odontoid screw placement, the patient underwent an anterior cervical discectomy and fusion for a fracture and disc herniation at $\mathrm{C6}-7$. The EBL and procedure times specific to odontoid screw fixation for this case were not available, as only composite data for the entire case were reported (total EBL $200 \mathrm{ml}$, procedural time $195 \mathrm{mins}$ ). For navigated cases, no difference was noted when comparing the mean procedural time for the first half of cases to the latter half of cases $(p=0.21)$. An equal number of patients were discharged to home versus rehabilitation across the entire population.

The mean and median follow-up time was 10.1 and 10.0 months, respectively. One patient from each group had a radiographically documented nonunion. In the case in which navigation was not used, the patient underwent subsequent occipitocervical fusion, whereas the case in which navigation was used, the patient remained asymptomatic. Another occipitocervical fusion was performed in a navigated case for odontoid screw retraction. No patient reported a worsening of symptoms at the most recent follow-up.

\section{Illustrative Cases \\ Case 1}

A 57-year-old man fell from a standing position after a syncopal episode and presented to the emergency department with neck pain. His left deltoid muscle exhibited Grade 4/5 strength due to a prior traumatic shoulder injury, and he was otherwise without new neurological deficit. A CT scan of the cervical spine showed an isolated Type II odontoid fracture with $2 \mathrm{~mm}$ of posterior displacement and favorable oblique fracture orientation for placement of an odontoid screw (Fig. 7A). The patient underwent anterior odontoid fixation using the $\mathrm{O}$-arm navigation system following our institutional protocol, without complication. An intraoperative $\mathrm{O}$-arm spin confirmed satisfactory placement of the odontoid screw (Fig. 7B). The patient was discharged to rehabilitation on the 3rd postoperative day. At the 5-month follow-up, plain radiography of his cervical spine (Fig. 7C) showed good union across the fracture site and his neck pain had resolved.

\section{Case 2}

A 16-year-old girl presented to the trauma bay after a motor vehicle collision in which she was an unrestrained rear seat passenger with a prolonged extraction time. Associated injuries included pelvic fracture and splenic laceration. CT of the cervical spine showed a Type II odontoid fracture with $2 \mathrm{~mm}$ of anterior displacement relative to the C-2 body with an oblique fracture orientation. Following medical stabilization, she underwent $\mathrm{O}$-arm-navigated odontoid screw placement without complication. Sagittal cervical CT scans obtained on postoperative Day 1 showed good screw position. The patient remained asymptomatic from her odontoid fracture. Follow-up CT 15 months after surgery showed solid osseous union of the dens.

\section{Case 3}

A 77-year-old man with a history of multiple falls from standing presented to the emergency department with neck pain. CT of the cervical spine showed a nondisplaced Type II odontoid fracture. The patient was taken for $\mathrm{O}$ arm-navigated anterior odontoid fixation. A postoperative cervical radiograph showed good screw position. Three days after surgery, the patient developed right-sided neck pain and dysphagia. A CT scan of the neck showed a neck hematoma, and the patient was taken for surgical evacuation of the hematoma. He remained without neurological deficit. At the 1.5-month follow-up, he returned after several falls with severe neck pain. A CT scan showed a displaced fracture of C-2 with the odontoid screw partially extruded into the prevertebral soft tissues anterior to C-3. He was taken for odontoid screw removal and uncomplicated occipitocervical instrumented fusion. His neck pain had improved but was still present 2 months after most recent surgery.

\section{Surgical Pitfalls and Alternatives}

Several steps may be taken to increase the likelihood of successful O-arm-navigated hardware placement. The $\mathrm{O}$ arm should be focused over the region of interest to ensure optimal image quality. ${ }^{25}$ We recommend clamping the passive reference frame directly to the Vertek arm rather than placing it directly on the patient, which increases the risk of frame movement in relation to the patient during surgery. Excessive movement should be avoided in all navigated cases. Also, several surgeons leave the retractor blades in the wound during the O-arm spin to avoid possible movement during reinsertion. Should movement of the reference frame occur or bones across a fracture site shift, especially in the mobile cervical spine, a repeat $\mathrm{O}$ arm spin should be performed whenever there is concern 
TABLE 1. Patient characteristics, surgical variables, and outcomes after navigated and nonnavigated anterior odontoid fixation

\begin{tabular}{|c|c|c|c|c|c|c|c|c|c|c|}
\hline $\begin{array}{l}\text { Case } \\
\text { No. }\end{array}$ & $\begin{array}{l}\text { Age } \\
\text { (yrs), } \\
\text { Sex }\end{array}$ & $\begin{array}{c}\text { Mechanism of } \\
\text { injury }\end{array}$ & $\begin{array}{l}\text { Presenting } \\
\text { Symptoms/ } \\
\text { Neuro Deficit }\end{array}$ & $\begin{array}{c}\text { EBL }(\mathrm{ml}) / \\
\text { OR Time } \\
\text { (mins) }\end{array}$ & $\begin{array}{l}\text { Discharge } \\
\text { Destination }\end{array}$ & $\begin{array}{c}\text { FU } \\
(\mathrm{mos})\end{array}$ & $\begin{array}{c}\text { Postop } \\
\text { Complications }\end{array}$ & $\begin{array}{l}\text { Postop } \\
\text { Imaging } \\
\text { Findings }\end{array}$ & $\begin{array}{l}\text { Subsequent } \\
\text { Surgery }\end{array}$ & $\begin{array}{l}\text { Outcome/ } \\
\text { EQ-5D* }\end{array}$ \\
\hline \multicolumn{11}{|c|}{ O-arm neuronavigation } \\
\hline 2 & $53, \mathrm{M}$ & $\begin{array}{l}\text { Bicyclist struck } \\
\text { by vehicle }\end{array}$ & None/none & NA & Home & 12 & None & $\begin{array}{l}\text { Fusion, normal } \\
\text { alignment }\end{array}$ & None & $\begin{array}{l}\text { Stable/1, 1, } 1 \\
\quad 1,2\end{array}$ \\
\hline 4 & $54, \mathrm{~F}$ & $\begin{array}{l}\text { Fall down } \\
\text { steps }\end{array}$ & $\begin{array}{l}\text { Neck pain/ } \\
\text { none }\end{array}$ & $60 / 116$ & Home & 34 & None & $\begin{array}{l}\text { Fusion, } \\
\text { minimally } \\
\text { displaced }\end{array}$ & None & $\begin{array}{l}\text { Neck pain } \\
\text { resolved/1,1, } \\
1,2,1\end{array}$ \\
\hline 5 & $78, \mathrm{~F}$ & $\begin{array}{l}\text { Fall from } \\
\text { standing }\end{array}$ & $\begin{array}{l}\text { Neck pain/ } \\
\text { none }\end{array}$ & $50 / 119$ & Rehab & 3 & None & $\begin{array}{l}\text { Fusion, normal } \\
\text { alignment }\end{array}$ & None & $\begin{array}{l}\text { Neck pain } \\
\text { resolved/2, } 2 \text {, } \\
1,1,1\end{array}$ \\
\hline 6 & $40, M$ & ATV accident & $\begin{array}{l}\text { Neck pain/ } \\
\text { none }\end{array}$ & $30 / 168$ & Home & 10 & None & $\begin{array}{l}\text { Nonunion, } \\
\text { minimally } \\
\text { displaced }\end{array}$ & None & $\begin{array}{l}\text { Neck pain } \\
\text { resolved/1,1, } \\
1,1,1\end{array}$ \\
\hline 7 & $16, F$ & MVC & None/none & $20 / 120$ & Home & 15 & None & $\begin{array}{l}\text { Fusion, normal } \\
\text { alignment }\end{array}$ & None & $\begin{array}{l}\text { Stable/1, 1, } 1 \\
\quad 1,1\end{array}$ \\
\hline 8 & $77, \mathrm{M}$ & $\begin{array}{l}\text { Fall from } \\
\text { standing }\end{array}$ & $\begin{array}{l}\text { Neck pain/ } \\
\text { none }\end{array}$ & $75 / 153$ & Rehab & 12 & $\begin{array}{l}\text { Neck hema- } \\
\text { toma }\end{array}$ & $\begin{array}{l}\text { Retracted } \\
\text { odontoid } \\
\text { screw }\end{array}$ & $\begin{array}{l}\text { Hematoma evacu- } \\
\text { ation, occiput- } \\
\text { C3 fusion }\end{array}$ & $\begin{array}{l}\text { Neck pain } \\
\text { improved/2, } \\
2,2,2,1\end{array}$ \\
\hline 9 & $84, \mathrm{M}$ & $\begin{array}{l}\text { Fall down } \\
\text { steps }\end{array}$ & None/none & $<5 / 122$ & Rehab & 3 & $\begin{array}{l}\text { Pre-existing } \\
\text { dysphagia }\end{array}$ & $\begin{array}{l}\text { Fusion, normal } \\
\text { alignment }\end{array}$ & PEG & $\begin{array}{l}\text { Back pain from } \\
\text { metastases/3, } \\
2,2,2,1\end{array}$ \\
\hline 10 & $57, \mathrm{M}$ & $\begin{array}{l}\text { Fall from } \\
\text { standing }\end{array}$ & $\begin{array}{l}\text { Neck pain/ } \\
\text { chronic } \\
\text { Grade } 4 / 5 \\
\text { It deltoid } \\
\text { strength }\end{array}$ & $50 / 167$ & Rehab & 5 & None & $\begin{array}{l}\text { Fusion, } \\
\text { minimally } \\
\text { displaced }\end{array}$ & None & $\begin{array}{l}\text { Neck pain } \\
\text { resolved/2,2, } \\
1,2,1\end{array}$ \\
\hline \multicolumn{11}{|c|}{ No O-arm neuronavigation } \\
\hline 1 & $67, \mathrm{M}$ & $\begin{array}{l}\text { Fall from } \\
\text { standing }\end{array}$ & $\begin{array}{l}\text { Neck pain/ } \\
\text { none }\end{array}$ & $50 / 279$ & Home & 1 & $\begin{array}{l}\text { Partial vocal } \\
\text { cord } \\
\text { paralysis }\end{array}$ & $\begin{array}{l}\text { Fusion, normal } \\
\text { alignment }\end{array}$ & PEG & $\begin{array}{l}\text { Neck pain } \\
\text { improved/1, 2, } \\
2,1,1\end{array}$ \\
\hline 3 & $80, \mathrm{M}$ & $\begin{array}{l}\text { Fall from } \\
\text { standing }\end{array}$ & $\begin{array}{l}\text { Neck pain/ } \\
\text { none }\end{array}$ & $35 / 119$ & Rehab & 11 & None & $\begin{array}{l}\text { Nonunion, } \\
\text { minimally } \\
\text { displaced }\end{array}$ & $\begin{array}{l}\text { Occiput-C3 } \\
\text { fusion }\end{array}$ & $\begin{array}{l}\text { Continued neck } \\
\text { pain/2, 2, 2, } \\
2,1\end{array}$ \\
\hline
\end{tabular}

ATV = all-terrain vehicle; FU = follow-up; MVC = motor vehicle collision; NA = not available; Neuro = neurological.

* EQ-5D assesses five dimensions (mobility, self-care, usual activities, pain/discomfort, anxiety/depression) and each dimension is assigned a numeric value as follows: 1 = no problems, 2 = some or moderate problems, 3 = severe problems.

of a possible discrepancy between navigation data and confirmatory anatomical points. Furthermore, the O-arm does not provide continuous real time navigation. For that reason, after planning a trajectory, we recommend intermittent biplanar fluoroscopy using the O-arm at frequent intervals during odontoid screw insertion for feedback on any changes in anatomical alignment of the target. Although the Mayfield clamp is required for registration and navigation purposes, it may hinder intraoperative movements to facilitate fracture reduction. Should intermittent biplanar fluoroscopy show poor fracture reduction, the Mayfield clamp may be loosened to allow for extension or flexion at the neck, and biplanar fluoroscopy may be used to guide the remainder of the screw insertion. Finally, we recommend placing the camera near the head, as the Stealth camera must see both the reference frame and the navigated instruments.

\section{Discussion}

Whereas other groups have reported one to two cases of O-arm-navigated odontoid screw placement as part of larger series of C1-2 fractures, ${ }^{1,6,25}$ we describe our institutional protocol and report on 8 patients in whom odontoid screw placement was performed using $\mathrm{O}$-arm neuronavigation, which represents the largest series of this type, to our knowledge. The primary objective of the study was to provide a step-by-step guide to the placement of an odontoid screw using $\mathrm{O}$-arm navigation. For exploratory purposes, we examined our early experience with navigated cases compared with nonnavigated cases, noting that a direct comparison between the techniques is highly limited by the case numbers and by the retrospective nature of the study. We did not detect significant differences in complication rates between patients in whom the $\mathrm{O}$-arm was and 


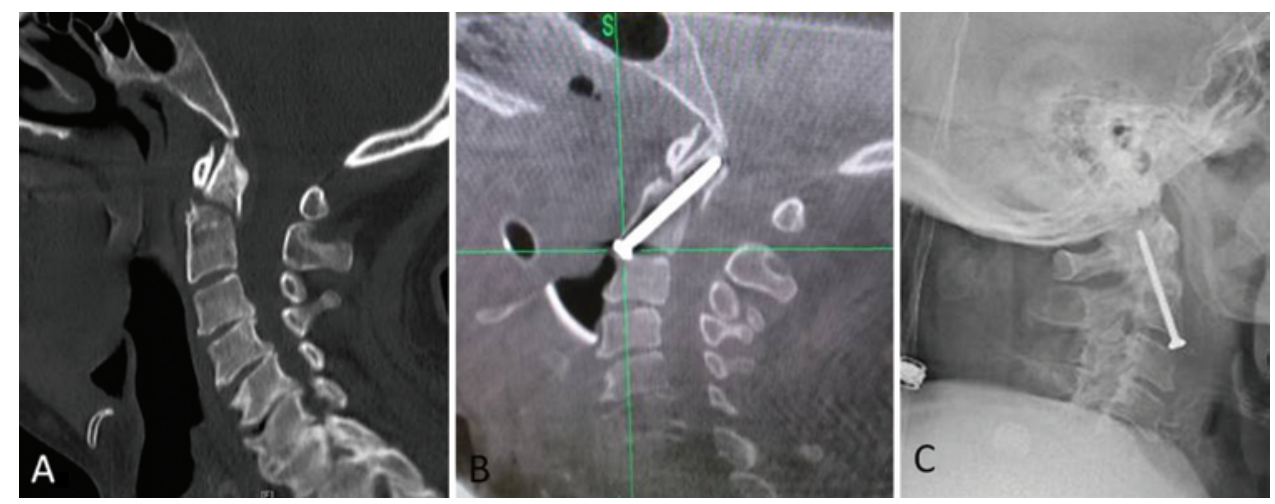

FIG. 7. Illustrative Case 1. A: Preoperative sagittal CT scan showing posteriorly displaced Type II odontoid fracture. B: Intraoperative $\mathrm{O}$-arm spin-generated sagittal image demonstrating position of the odontoid screw. C: Plain lateral cervical radiograph demonstrating stable screw position at the 5-month follow-up. Figure is available in color online only.

those in whom it was not used as an adjunct, although our numbers are still small. Similar to other O-arm-assisted studies of anterior odontoid fixation, no screws required immediate replacement. However, as in two other studies involving navigated odontoid screw placement, screw loosening and dislocation into the prevertebral soft tissue was noted in one patient and required posterior occipitocervical fusion. ${ }^{17,26}$ We did not detect a difference in outcome between either group of patients, although our study was not powered to detect such a difference. Despite an institutional, standardized protocol for navigated screw placement, a single surgeon did not perform all cases. Potential variability among the 4 surgeons who performed all procedures in this series, combined with the relatively small sample size, may explain why the procedure duration did not significantly decrease over time following adoption of the $\mathrm{O}$-arm, as it has in other studies. Other groups have demonstrated a learning curve and reductions in procedural time after 7 cases. ${ }^{29}$ Additional limitations of our study include its retrospective nature, including the retrospective collection of EQ-5D measures, and lack of randomization. However, our review of our institutional experience and comparisons between navigated and nonnavigated groups was primarily intended for teaching and exploratory purposes.

Using the $\mathrm{O}$-arm with navigation for anterior odontoid screw fixation may offer potential benefits compared with free-hand and fluoroscopy-based techniques, based on the prior literature for screw placement in other parts of the spinal column. For the patient, advantages of the $\mathrm{O}$-arm include increased accuracy of screw placement ${ }^{8,11}$ and the ability to perform an intraoperative CT to confirm the location of screw placement. ${ }^{18}$ Immediate correction in the operating room may be performed rather than during a subsequent surgery. For the surgeon, the O-arm may be used at the start of the case to guide reduction of the fracture and subsequent positioning, as well as to virtually plan the entry point and screw trajectory. Based on distortion of bony anatomy due to fracture, the trajectory can be altered during the procedure as well. ${ }^{6}$ In addition, the $\mathrm{O}$-arm offers ease in flipping between AP and lateral fluoroscopy and an increased ability to visualize the tip of the dens. For both the patient and the surgical team, other authors have reported a decrease in fluoroscopy time and ionizing radiation exposure when using intraoperative navigation systems compared with fluoroscopy alone. ${ }^{28}$

Several case series document the safety of navigated odontoid screw placement using precursors to the O-arm and suggest possible improved outcomes compared with conventional techniques. The majority of studies have compared fluoroscopy-based techniques to the Iso-C system, which is a precursor navigation system that generates a $3 \mathrm{D}$ reconstruction of fluoroscopic images obtained from a modified C-arm system..$^{25}$ For instance, Martirosyan et al. compared biplanar fluoroscopy-guided anterior screw fixation of odontoid fractures in 25 patients with Iso-Cguided anterior screw fixation in 26 patients. Surgical complication rates and clinical outcomes were also similar between the groups. Rates of fusion across the fracture site were higher and duration of surgery was lower in the Iso-C group compared with the biplanar fluoroscopy group, although the findings did not reach statistical significance. ${ }^{18}$ In another study of 29 patients undergoing Iso-C-assisted odontoid screw placement versus historical controls using conventional fluoroscopy, similar rates of fusion, complications, and favorable outcomes were observed. ${ }^{28}$ Shorter fluoroscopy times were observed in the Iso-C group (42.9 seconds) as compared with the historical controls (68.1 seconds) with no difference in overall operative times. In 3 additional cases series using Iso-C, ${ }^{17,26,29}$ no screw revisions were required, although one study reported 3 minor breaches that were clinically silent. Taken together, studies with Iso-C confirm the findings of our study that navigation results in no increase in complications and may offer several improvements compared with fluoroscopic techniques.

The accuracy and safety of O-arm navigation as an adjunct in anterior odontoid screw fixation is demonstrated in larger studies evaluating the $\mathrm{O}$-arm in the treatment of C1-2 fractures in which patients with Type II odontoid fractures are a subset. In a series of 17 patients with $\mathrm{C} 1-2$ traumatic fractures, 2 patients underwent $\mathrm{O}$-arm-navigated odontoid fixation. Intraoperative CT scans showed that $92.6 \%$ of all screws were correctly placed, with a single screw requiring correction. No vascular injury or implant failure was observed, and both odontoid screws showed no perforation or need for replacement. ${ }^{6}$ In another mixed 
series, 2 of 25 patients underwent odontoid screw placement by the $\mathrm{O}$-arm, and again there was no screw misplacement or canal breaches. ${ }^{1}$ Finally, in a cohort of spine trauma patients undergoing $\mathrm{O}$-arm-assisted navigation for screw placement, no patient had iatrogenic neurovascular injury or required screw revision, whereas the revision rate was $1.2 \%$ in the nonnavigated group. ${ }^{25}$ Two patients in the cohort successfully underwent $\mathrm{O}$-arm-navigated odontoid screw placement.

Despite the safety and effectiveness of $\mathrm{O}$-arm navigation for odontoid screw placement, its use may be associated with several obstacles. First, the $\mathrm{O}$-arm is large and more expensive than $\mathrm{C}$-arm systems and requires institutional accommodations for its use. ${ }^{16,18}$ Use of the O-arm is associated with a learning curve, and O-arm set-up time may initially be greater than conventional systems; however, institutional familiarity with the technology will likely lead to reductions in preparation times. For instance, we noted a trend toward shorter times for navigated versus nonnavigated cases. Furthermore, radiation exposure to the patient and operative team during the initial O-arm spin and subsequent acquisitions is a continual concern. Such exposures can be reduced by not repeating a formal postoperative CT scan unless clinically indicated and by the surgical team leaving the room during image acquisition. In addition, the O-arm currently relies on optical tracking, which can lead to line-of-sight issues between the camera and the instruments. Although electromagnetic tracking is available, its role is currently limited in spine surgery due to interference generated by the metallic hardware being placed. Finally, although the use of navigational adjuncts can help to guide screw placement and avoid injury to surrounding structures, rates of screw misplacement are not reduced to zero. Thus, the O-arm is meant to complement screw placement technique and is not a substitute for an intimate understanding of surgical anatomy or surgeon experience.

\section{Conclusions}

As odontoid fractures become increasingly common among the aging population, ${ }^{21}$ a technical understanding of surgical treatment options, including anterior odontoid screw fixation, is critical. We present in a step-by-step fashion our standardized protocol for the use of O-arm navigation as an adjunct to anterior screw fixation of Type II odontoid fractures, along with illustrative cases. Based on our initial surgical experience with and without O-arm navigation, complication rates and outcome following anterior odontoid fixation did not appear to be noticeably worse among navigated screw cases compared with nonnavigated cases. Also, there was no significant difference between EBL and procedural times between the groups. Such retrospective studies are needed to establish safety prior to adoption of a new adjunctive technique in a specific patient population. Larger, prospective studies will be better able to determine whether the proposed advantages of $\mathrm{O}$-arm navigation, as seen in posterior cervical fusions, will translate into more accurate and efficient screw placement in patients with odontoid fractures, and, ultimately to improved patient outcomes.

\section{References}

1. Ailawadhi P, Agrawal D, Satyarthee GD, Gupta D, Sinha S, Mahapatra AK: Use of O-arm for spinal surgery in academic institution in India: experience from JPN apex trauma centre. Neurol India 59:590-593, 2011

2. Anderson LD, D'Alonzo RT: Fractures of the odontoid process of the axis. J Bone Joint Surg Am 56:1663-1674, 1974

3. Battaglia TC, Tannoury T, Crowl AC, Chan DP, Anderson DG: A cadaveric study comparing standard fluoroscopy with fluoroscopy-based computer navigation for screw fixation of the odontoid. J Surg Orthop Adv 14:175-180, 2005

4. Böhler J: Anterior stabilization for acute fractures and nonunions of the dens. J Bone Joint Surg Am 64:18-27, 1982

5. Brooks AL, Jenkins EB: Atlanto-axial arthrodesis by the wedge compression method. J Bone Joint Surg Am 60:279_ 284, 1978

6. Costa F, Ortolina A, Attuati L, Cardia A, Tomei M, Riva $\mathrm{M}$, et al: Management of $\mathrm{C} 1-2$ traumatic fractures using an intraoperative 3D imaging-based navigation system. J Neurosurg Spine 22:128-133, 2015

7. Denaro V, Papalia R, Di Martino A, Denaro L, Maffulli N: The best surgical treatment for type II fractures of the dens is still controversial. Clin Orthop Relat Res 469:742-750, 2011

8. Epstein NE: Commentary: Utility of the O-arm in spinal surgery. Surg Neurol Int 5 (Suppl 15):S517-S519, 2014

9. Fan Chiang CY, Tsai TT, Chen LH, Lai PL, Fu TS, Niu CC, et al: Computed tomography-based navigation-assisted pedicle screw insertion for thoracic and lumbar spine fractures. Chang Gung Med J 35:332-338, 2012

10. Gallie WE: Fracture and dislocations of the cervical spine. Am J Surg 46:495-499, 1939

11. Guppy KH, Chakrabarti I, Banerjee A: The use of intraoperative navigation for complex upper cervical spine surgery. Neurosurg Focus 36(3):E5, 2014

12. Hadley MN, Walters BC, Grabb PA, Oyesiku NM, Przybylski GJ, Resnick DK, et al: Guidelines for the management of acute cervical spine and spinal cord injuries. Clin Neurosurg 49:407-498, 2002

13. Haid RW Jr: C1-C2 transarticular screw fixation: technical aspects. Neurosurgery 49:71-74, 2001

14. Harms J, Melcher RP: Posterior C1-C2 fusion with polyaxial screw and rod fixation. Spine (Phila Pa 1976) 26:2467-2471, 2001

15. Holly LT, Foley KT: Image guidance in spine surgery. Orthop Clin North Am 38:451-461, abstract viii, 2007

16. Ishikawa Y, Kanemura T, Yoshida G, Matsumoto A, Ito Z, Tauchi R, et al: Intraoperative, full-rotation, three-dimensional image (O-arm)-based navigation system for cervical pedicle screw insertion. J Neurosurg Spine 15:472-478, 2011

17. Kantelhardt SR, Keric N, Giese A: Management of C2 fractures using Iso-C(3D) guidance: a single institution's experience. Acta Neurochir (Wien) 154:1781-1787, 2012

18. Martirosyan NL, Kalb S, Cavalcanti DD, Lochhead RA, Uschold TD, Loh A, et al: Comparative analysis of isocentric 3-dimensional C-arm fluoroscopy and biplanar fluoroscopy for anterior screw fixation in odontoid fractures. J Spinal Disord Tech 26:189-193, 2013

19. Mattei TA, Fassett DR: The O-arm revolution in spine surgery. J Neurosurg Spine 19:644-647, 2013 (Letter)

20. Pirris SM, Nottmeier EW: A case series on the technical use of three-dimensional image guidance in subaxial anterior cervical surgery. Int J Med Robot 11:44-51, 2015

21. Platzer P, Thalhammer G, Oberleitner G, Schuster R, Vécsei V, Gaebler C: Surgical treatment of dens fractures in elderly patients. J Bone Joint Surg Am 89:1716-1722, 2007

22. Ryan MD, Henderson JJ: The epidemiology of fractures and fracture-dislocations of the cervical spine. Injury 23:38-40, 1992

23. Ryken TC, Hadley MN, Aarabi B, Dhall SS, Gelb DE, Hurl- 
bert RJ, et al: Management of isolated fractures of the axis in adults. Neurosurgery 72 (Suppl 2):132-150, 2013

24. Sawarkar DP, Singh PK, Siddique SA, Agrawal D, Satyarthee GD, Gupta DK, et al: Surgical management of odontoid fractures at level one trauma center: a single-center series of 142 cases. Neurol India 63:40-48, 2015

25. Schouten R, Lee R, Boyd M, Paquette S, Dvorak M, Kwon $\mathrm{BK}$, et al: Intra-operative cone-beam CT (O-arm) and stereotactic navigation in acute spinal trauma surgery. J Clin Neurosci 19:1137-1143, 2012

26. Summers LE, Kouri JG, Yang M, Patrick Jacob R: Odontoid screw placement using isocentric 3-dimensional C-arm fluoroscopy. J Spinal Disord Tech 21:45-48, 2008

27. Watkins RG, Gupta A, Watkins RG: Cost-effectiveness of image-guided spine surgery. Open Orthop J 4:228-233, 2010

28. Yang YL, Fu BS, Li RW, Smith PN, Mu WD, Li LX, et al: Anterior single screw fixation of odontoid fracture with intraoperative Iso-C 3-dimensional imaging. Eur Spine J 20:1899-1907, 2011

29. Zou D, Zhang K, Ren Y, Wu Y, Yang Y, Li Y: Three-dimensional image navigation system-assisted anterior cervical screw fixation for treatment of acute odontoid fracture. Int J Clin Exp Med 7:4332-4336, 2014

\section{Disclosures}

The authors report no conflict of interest concerning the materials or methods used in this study or the findings specified in this paper.

\section{Author Contributions}

Conception and design: Pisapia, Malhotra, Chen, Schuster. Acquisition of data: Pisapia, Salinas, Macyszyn, Lee, Lucas, Malhotra, Chen, Schuster. Analysis and interpretation of data: Pisapia, Chen, Schuster. Drafting the article: Pisapia. Critically revising the article: all authors. Reviewed submitted version of manuscript: Pisapia, Nayak, Macyszyn, Lee, Lucas, Malhotra, Chen, Schuster. Approved the final version of the manuscript on behalf of all authors: Pisapia. Statistical analysis: Pisapia. Administrative/technical/material support: Pisapia, Salinas. Study supervision: Chen, Schuster.

\section{Correspondence}

Jared M. Pisapia, Department of Neurosurgery, University of Pennsylvania, 3400 Spruce St., 3rd Fl. Silverstein Pavilion, Philadelphia,PA 19104.email: jared.pisapia@uphs.upenn.edu. 